\title{
Close family bonds and community distrust. The complex emotional experience of a young generation from southern Italy
}

Agostino Carbone, Immacolata Di Napoli, Fortuna Procentese \& Caterina Arcidiacono

To cite this article: Agostino Carbone, Immacolata Di Napoli, Fortuna Procentese \& Caterina Arcidiacono (2021): Close family bonds and community distrust. The complex emotional experience of a young generation from southern Italy, Journal of Youth Studies, DOI: 10.1080/13676261.2021.1939283

To link to this article: https://doi.org/10.1080/13676261.2021.1939283

曲 Published online: 10 Jun 2021.

Submit your article to this journal $\widetilde{ }$

Џll Article views: 55

Q View related articles 5

View Crossmark data \lceil 


\title{
Close family bonds and community distrust. The complex emotional experience of a young generation from southern Italy
}

\author{
Agostino Carbone (D) ${ }^{\mathrm{a}}$, Immacolata Di Napoli (1) ${ }^{\mathrm{b}}$, Fortuna Procentese $\mathbb{( 1 D}^{\mathrm{b}}$ and \\ Caterina Arcidiacono (1D ${ }^{\mathrm{b}}$
}

${ }^{a}$ Department of Social and Developmental Psychology, Sapienza University of Rome, Italy; ${ }^{\text {b Division of }}$ Psychology and Education, University of Naples Federico II, Italy

\begin{abstract}
For decades, scientific literature has highlighted the discomfort and delay of the transition to adulthood of the young generations of southern Italy. This article examines the experience of the current young generation, strongly disadvantaged by structural factors of their environment, like crime and unemployment, and by a familistic culture. This study involved 160 young people (age range $=18-34$; $s d=4.242$ ) living in the metropolitan area of Naples. They were asked to describe their emotional relations with their community of belonging, their family bonds and their aspirations for the future. Data were collected qualitatively and analyzed through a psychological textual analysis (Emotional Textual Analysis) aimed at capturing the emotionality through which these youths attribute meaning to their reality and make decisions. Results show a generation left alone with its goals; in fact, the presence of crime inhibits the ability to plan the future, while the family of origin is mostly focused on keeping the younger generations inside to defend themselves against the instability of the outside world. In these circumstances, relations with peers and higher education function exclusively as a condition of pervasive presentification, in which to continue living within the role of eternal young people and students.
\end{abstract}

\section{ARTICLE HISTORY}

Received 7 January 2020 Accepted 1 June 2021

\section{KEYWORDS}

Youth culture; emotional bonds; presentification; crime; Italy

\section{Introduction}

Recent studies have highlighted an innovative reorganization of the forms of coexistence and the expectations of young people that go beyond the traditional concepts of youth development marked by the achievement of evolutionary stages and significant milestones (Leccardi, Cuzzocrea, and Bello 2018; Paniccia et al. 2019; Recksiedler and Settersten 2020; Sanderson 2020). In this conception, the age of youth is not considered as a transitory, albeit jagged, moment that precludes adulthood. 
Rather, our interest focuses on the search for cultures that, in different ways, today's young people have developed in relation to the multiple and complex space-time conditions that characterize living in postmodernity (Harvey 2001).

This study aims to reinterpret the framework of youth research by analyzing the characteristics of youth in a metropolitan area of southern Italy (Naples), focusing specifically on the role of belonging to this specific context in orienting how young Neapolitans experience social relationships, make decisions in relation to their own self-realization, participate in the social life of the community, imagine their future in relation to family ties, and build their work and sentimental aspirations, as they intend to pursue economic independence and entry into a tight labor market.

Discovering that the classically desirable stages for Western youth no longer guide the reorganization of the life goals of people considered 'young' has two important implications. The first is that the models that until now have looked at youth as an emancipatory process need to be reviewed using theoretical and epistemological approaches that take into account the evidence produced by the very recent scientific literature that deconstructs the universal concept of youth (Wyn and White 1996). The second, which acts as a corollary, is that the same theoretical models that have described the linearity of the evolutionary paths of young people in the '70s,' 80s, and '90s in Western societies (Leccardi 2005; Cavalli and Leccardi 2013) are to be contextualized and to be considered themselves as 'grounded' in that specific historical, social and political period, permeated by the idea of unlimited progress and growth in the industrial and civil rights fields.

At this point, it is necessary to recover local aspects that inform the new cultures of young people in order to better understand the way in which the latter give meaning to the profound changes in our societies and the way in which they organize the present relationship to future expectations that the context allows them to imagine (Leccardi 2005).

\section{Theoretical framework}

Recently, within youth studies, the need to recover the relationship between the various forms of belonging to local contexts that young people experience in their daily routine has emerged (Habib and Ward 2019a; 2019b). This effort is aimed at bridging a gap in the literature in order to deepen some youth realities (Wyn, Cuervo, and Cook 2018) that differ from national or international dimensions studied, as in our case (Bello and Cuzzocrea 2018), for example through the concept of globalization. We consider youth as a socially situated social process where young people embody emotional relationships with their groups, people and environments (Leccardi, Cuzzocrea, and Bello 2018; Habib and Ward 2019a)

Even not assuming youth as a life stage, some scholars focus on the concept of transition into adulthood, considering it as a contextualized process, characterized by more fragmentation and de-standardization than in the past (EGRIS 2001; Cops, Pleysier, and Put 2012; Nico 2014). Becoming an adult is, in fact, increasingly difficult (Arnett, Žukauskienè, and Sugimura 2014; Mary 2014) and more individualistic than in the past (Schwartz, Côté, and Arnett 2005), especially now that institutional and collective support is lacking and there is an absence of external guidance (Côté and Bynner 2008).

Moreover, scholars have thoroughly investigated the personal expectations of young people with respect to the future in a social and economic context characterized by 
uncertainty (Leccardi 2008; 2012; 2005; Heggli, Haukanes, and Tjomsland 2013; Cairns, Growiec, and de Almeida Alves 2014; Bryant and Ellard 2015; Cuzzocrea and Mandich 2016; Howie and Campbell 2016; Sica et al. 2016; Schoon and Mortimer 2017). According to Kintrea, St Clair, and Houston (2015), personal aspirations toward the future and attitudes towards personal development and one's own work are influenced by territorial contexts. Recently, Leccardi $(2020 ; 2017)$, analyzing the profound transformation of youth culture in the Mediterranean area, highlighted that the feeling of uncertainty characterizing many young people today is the result of the 'difficulty of establishing a positive relationship with the future' (Leccardi 2020, 171). The lack of trust in the living context, and the perception of poor social and community support, induce individuals to fall back on their own individual resources for their personal planning (Montella et al. 2019; Di Napoli, Dolce, and Arcidiacono 2019a, b). Moreover, the lack of contextual opportunities induces a sense of disengagement towards community participation and, consequently, feelings of isolation, lack of interest and distrust (Di Blasi et al. 2016; Di Napoli, Procentese, and Arcidiacono 2019c).

Conversely, the opportunities to participate in collective actions lead to the most positive development and individual growth, particularly in the adulthood emergence phase (Tyrell and Yates 2018).

Recent literature specifically highlights the importance of the spaces and territorial contexts in which people live (Shildrick, Blackman, and MacDonald 2009; Cuervo and Wyn 2014; Farrugia 2019), stressing the role of the geographical dimension in youth transition into adulthood and conceptualizing the factors influencing youth agency (Cairns 2014).

Individual, organizational and cultural factors should be considered in studying youth cultures (Di Martino et al. 2018; Galli et al. 2019; Giardiello 2020), as well as taking into account the sense of belonging and attachment to local places (Hernandez et al. 2007; Bernardo and Palma-Oliveira 2012; Cook and Woodman 2020) and their emotional bonds (Anton and Lawrence 2014). In this vein, several studies by this research team have specifically examined the role of community distrust and emotional place bonds, investigating these specific youth cultures (Arcidiacono, Procentese, and Di Napoli 2007; Di Napoli et al. 2019b; Ravn and Demant 2017).

Some case studies make what has been said so far emblematic. The local cultures of young people are in a continuous and fast evolution all over the globe, taking on more and more characteristics that lead to failure in terms of the traditional goals of the youth. In Europe, for instance, a recent study has highlighted the feeling of frustration of young Serbs in imagining their future and how the perception of the scarce resources in their life context have induced them to review their future aspirations (Anđić 2020). In Southern societies like Spain, Portugal, Greece and Mexico, new patterns have been experienced due to a complexity of factors related to access to decent work opportunities, (Feixa et al. 2012; Serracant 2012; Cairns, Growiec, and de Almeida Alves 2014; Saraví 2014; Cairns et al. 2016).

\section{The Italian context}

Some characteristics of the research context, described below, will help with an understanding of the factors involved in the definition of the characteristic youth culture taken into consideration.

In Italy, the debate on youth studies focuses specifically on two points. 
1) The delay in the transition to adulthood compared to the European average and other European countries due to structural factors (i.e. high levels of job insecurity, unemployment, weak youth policies) (Molgat 2007; Andres and Adamuti-Trache 2008). Leccardi (2006) has highlighted that young Italians have greatly changed their way of experiencing time, thus leading to a sense of living in an 'extended present'.

2) The role of the family of origin in relation to the autonomy of their offspring. On this last point, different points of view and interpretations of the phenomenon coexist, sometimes in conflict. In some cases, the family is attributed a role in which the young can find comfort and protection (León and Migliavacca 2013; Alfieri et al. 2014; Crocetti and Meeus 2014; Piumatti et al. 2014; Sica et al. 2016). In other cases, the bond between parents and children is considered too close and sometimes indissoluble, also contributing to the perpetuation of 'patriarchal' and sexist ideologies (Fasanelli et al. 2020).

More specifically, the research focuses on Southern Italy, in the Campania Region, precisely the Province of Naples, considering 91 municipalities that since 2015 have merged with Naples into the Metropolitan City of Naples.

Campania is the 'youngest' Italian region and is also the national region with the second largest number of young unemployed people. EUROSTAT (2018) indicates that its youth unemployment rate reached 54.7 per cent in 2017, positioning it at seventh place among the European regions with the highest rate of youth unemployment. In general, the whole of southern Italy has a decidedly alarming 51.6 per cent average rate of unemployment, especially when compared to the national (32.6\%) and EU-28 (15.2\%) average rates. Furthermore, the situation in this region is also aggravated by the increase in the poverty rate, rising from 19.5 per cent in 2016-24.4 in 2017, and the alarmingly low rate of tertiary educational attainment (26.9\%) - the lowest in Europe. Leone and Rubin (2019) in the Toniolo Report, specifically highlighted that in the Campania region more than $70 \%$ of youths are still cohabiting with their parents, have difficulties in their relational lives, and are mostly unemployed or with non-formalized jobs (four time more than in the rest of the country) (ISTAT 2019; Rosina 2019). Indeed (SVIMEZ 2019), in this regional context, young people, more so than the other young Italians, leave their parents' home much later compared to the average in other European countries.

In addition, The Metropolitan City of Naples is the area with a higher incidence of violent crime in Italy (EUROSTAT 2018; ISTAT 2019) and a high rate of dissolution of local administrations due to mafia infiltrations. Moreover, people engaged in non-profit organizations and volunteering are under the national average. In addition, in describing this context one must consider low women's employment rate, and high level of distrust in institutions, expressed also by a reduced level of people who regularly cast their votes.

\section{The current study}

The general aim of this study is to describe the youth culture of the Metropolitan City of Naples, collecting the emotional connotations through which the local young people attribute a symbolic meaning (Salvatore and Freda 2011) to their context of belonging, and considering how this affects their development. In particular we are oriented to deepen understanding of how the young people negotiate with their surroundings 
and shape their lives and the quality of connection with their worlds (Habib and Ward 2019c). The specific objectives of the study were: a) to explore the family relationships between young people and their parents and how this affects their permanence in the home of origin and the desire to form their own family; b) investigate how a high level of unemployment influences young people's career and training choices; c) study how the effects of community distrust and the decay of the local environment influences collective participation, the feeling of agency and engagement in prosocial actions of these young people.

\section{Methods}

\section{Participants}

Participants were young inhabitants of the Province of Naples $(n=160)$ aged 18-34 $(M=23)$. They are up to 35 years according to the most widely used definition of youth (Buzzi, Cavalli, and de Lillo 2007; Rosina 2019). Respondents were homogeneously recruited by gender, area of residence and age range (young people 18-23; youngadults 24-34) and belonged to the Millennial and $Z$ generations. Recruitment covered eight of the nine metropolitan areas, excluding Naples city and the main tourist destinations presenting a significantly lower unemployment rate. For each of the eight (8) suburban areas, twenty $(n=20)$ participants were recruited and at least one inhabitant for each municipality was involved. From each area, ten (10) women and ten (10) men were selected, comprising emergent adults, as well as youths experiencing delayed transition into adulthood. Regarding their educational level, most had obtained a high school diploma (74\%), 7 per cent were university graduates, and a few had only obtained the primary school diploma (3\%) or middle school diploma (16\%), and there were no significant differences between males and females. Regarding their employment status, 49 per cent were full-time students, 25 per cent unemployed or casual workers, 7 per cent employees or independent professionals, 5 per cent housewives, 4 per cent students with part-time jobs and $8 \%$ were NEETs (of which $5 \%$ were housewives). $21 \%$ were married and the others, almost all, coexisted in the family; a higher percentage of females was found among full time students (60\%) and casual workers (65\%). All respondents were white Italian citizens. As a limitation of this research, participants from minority groups were not selected, nor were political orientation or social engagement taken into consideration.

\section{Procedures}

Interviews were conducted by the 15 locally trained junior researchers who recruited participants in their neighborhood through a snowball sampling strategy. Data were collected between October 2017 and May 2018. The interviewers were trained to interact with the respondents, profiling the interview according to the participants' responses: questions were sufficiently general to cover a wide range of experiences and narrow enough to elicit and explore the participants' own experience. The interviews, conducted in private settings, lasted an hour on average. The research proposal and the related procedure were presented for approved by the departmental ethics commission. 


\section{Instrument for data gathering}

Data were collected through qualitative open interviews that collected participants' free narratives focused on: a) Representation and perception of living context; b) Emotional and professional connections: c) Personal projecting; e) Community projecting; and g) Magic Wand: ideal wishes and desires for the territorial community for the next 10 years. Questions were deliberately formulated at a very general level and phrased in an open-ended format. It was an open interview (Schütze 2014), but at the same time the discursive interactions were finalized to detect information focused on specific areas previously agreed upon among the researchers. A quantity of data equivalent to $940,816.00$ characters $(160,863.00$ words) was collected. The interviews were audio recorded, then transcribed verbatim and unified into a single corpus (not including the interviewers' words) and then analyzed (see below). Each interview was assigned illustrative variables (see Table 1) which summarize the personal characteristics of the interviewee deemed salient by the research group in relation to the research questions.

\section{Data analysis}

Emotional Textual Analysis (ETA) (Carli and Paniccia 2002; Carli et al. 2016; Paniccia et al. 2019; Bucci and Vanheule 2020) is a mixed method aimed at tracing the emerging emotional meanings produced through language by a person, a group, or in a text. From a theoretical-epistemological viewpoint, ETA rests on the idea that language reflects a double level of meaning, a cognitive one and an emotional one. In language there are words with little emotional value and others with a great emotional connotation. The latter are defined dense words. For example, words such as 'to go away', 'hatred', 'failure', or 'ambition' are characterized by a maximum of emotional density. In contrast, words like 'to go', 'to think', 'to do', like modal, auxiliary and widely used verbs, or many adverbs, have a low emotional profile and do not indicate emotions except, at times, within a sentence (Carli et al. 2016). These are considered non-dense. A word may acquire particular emotional relevance depending on the context, and thus, the dense words' selection is guided by knowledge of the local research context.

ETA is based on the detection of dense words in a large amount of textual material, and a group of dense words constitute complex emotional configurations (clusters of dense words). Identifying the emotionality of respondents as a unit of analysis allows us to know the implicit premise that prepares subsequent interpretative activities and interactions within a context: that is, their ways of interpreting events, evaluating and making decisions (Salvatore and Freda 2011). In other words, the ETA allows us to grasp the predictive aspects conveyed by emotions or particular emotional structures towards the future. In accordance with Salvatore and Freda (2011) we propose a semiotic

Table 1. Description of socio-demographic variables and possible values (modalities) associated to clusters.

\begin{tabular}{llllll}
\hline & \multicolumn{4}{c}{ Variables } \\
\cline { 2 - 5 } & Gender & Neighborhood size & Education & Origins & Age range \\
\hline Modalities & male & big & degree & native & young (18-24) \\
& female & small/medium & high school diploma & transferred & young-adult (24-34) \\
\hline
\end{tabular}


model of the mind (semiotic unconscious). By semiotic we mean a model of the mind as an ongoing process of meaning-making that mediates our relation to the world and takes places by means of semiotic devices (such as language), the effectiveness of which depends on social exchange. In this perspective, human beings build reality only through the emotions with which we symbolize reality itself. Therefore, not the events that evoke emotions, as much as the emotions that build events.

\section{Operative procedures}

ETA uses a specific procedure combining quantitative and qualitative data analysis. The qualitative part consists in selecting the dense words and in the interpretation of their co-occurrence in each cluster and of relationships between them (factors). On the other side, the quantitative part is carried out by textual analysis software, usually Alceste or T-Lab (Lancia 2012), which carries out a multi-dimensional statistical analysis of the textual corpus. More specifically, the statistical procedures underlying the multidimensional analysis used are: a) cluster analysis -which enables us to study how the dense words co-occur within the text, forming stable and significant repertoires based on the chi-square value $(x 2)$ of words (see table 2 ); b) factorial correspondence analysis- which measures the relationship between clusters expressed by cosines (Table 3 ) onto factorial axes in a multi-dimensional Euclidean space (see fig. 1). Each factor is defined by clusters that diverge most from each other (polarities of factors). For example, in a social context where young people commonly leave their home early, it could be assumed that two opposite clusters of a factor could be professional fulfilment on the one hand and family ties on the other.

The conclusive phase of ETA comprises a qualitative interpretation of the clusters and the polarities of factors (Carli and Paniccia 2002). The researcher's task was to give meaning to this new order of text organized by the logic of the co-occurrence of dense words in the text. Starting from the dense words with the greatest chi-square value in each cluster, the interpretation consisted mainly in identifying the emotional meaning of language and studying the etymology to retrieve their symbolic meaning beyond the literal sense (Carli and Paniccia 2002). An example is the word 'street', which we find in cluster 1 (see below) of this research, followed by the words 'mentality' and 'crime'. From an etymological point of view 'street' means a meeting place where young people talk about the difficulty of meeting their needs with a context governed by a criminal system.

The analysis was performed by researcher trained in ETA using the T-Lab software (Lancia 2012). At the end of the study, several consultations were devoted to discussing the results with the research team and the interviewed youths.

\section{Results}

Overall, of a total of 4,851 ECUs (Elementary Contest Units), 3,978 units (82\%) were classified in a stable way in the clustering process, which indicates a very good fit between model and data. The statistical analysis produced a factorial space with five factors and six clusters of dense words (Fig. 1)

For each cluster, words with the highest chi-square value were selected (Table 2). Clusters are shown in descending order of relevance (ECs \%). The factorial correspondence 


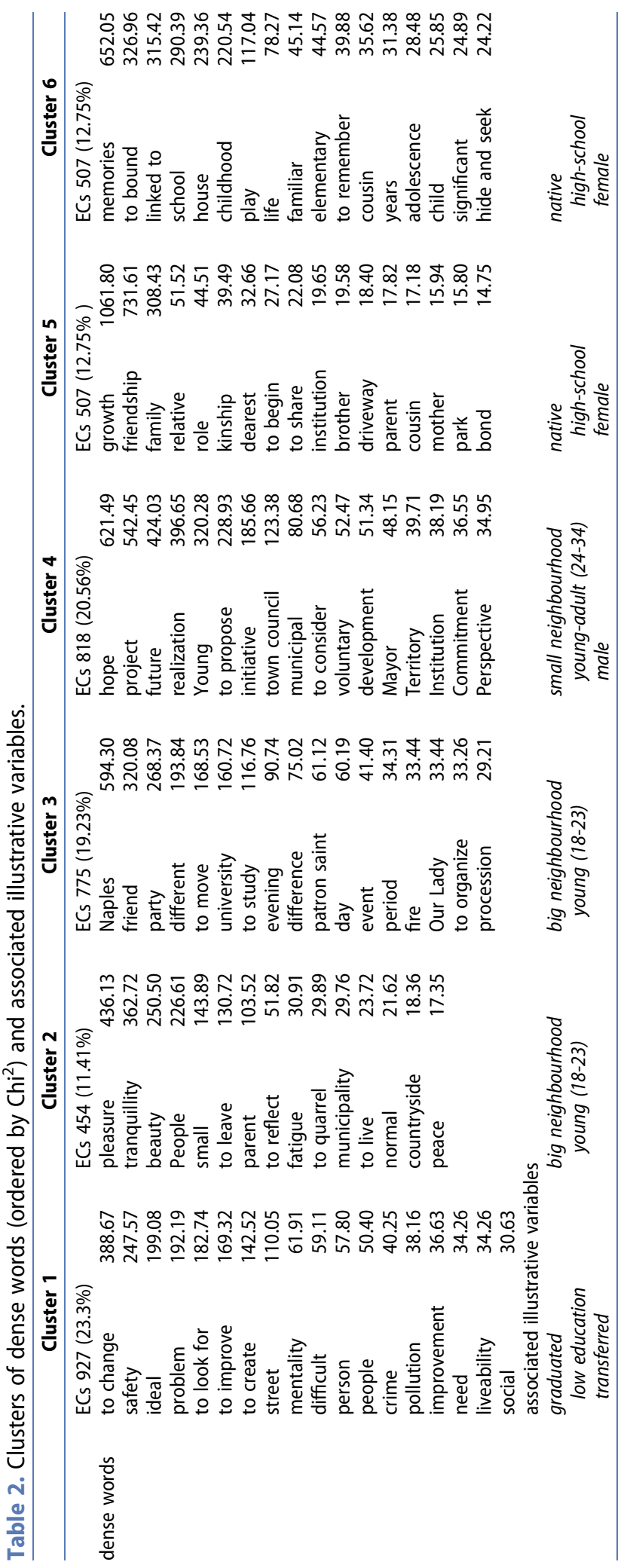


Table 3. Relationship between clusters and factors expressed by cosines.

\begin{tabular}{lllccc}
\hline & Factor 1 & Factor 2 & Factor 3 & Factor 4 & Factor 5 \\
\hline CL_01 & 0.4814 & 0.3177 & $\mathbf{0 . 6 9 0 3}$ & 0.2812 & 0.0579 \\
CL_02 & -0.2716 & 0.0223 & 0.3876 & $-\mathbf{0 . 8 3 2 6}$ & -0.3056 \\
CL_03 & -0.2749 & $\mathbf{0 . 5 5 5 0}$ & $-\mathbf{0 . 4 3 7 4}$ & 0.0548 & 0.0127 \\
CL_04 & $\mathbf{0 . 8 6 8 3}$ & 0.3887 & -0.4103 & -0.0834 & -0.0430 \\
CL_05 & -0.5220 & 0.4544 & 0.0886 & -0.0437 & $\mathbf{0 . 6 7 3 9}$ \\
CL_06 & $\mathbf{- 0 . 6 6 5 8}$ & $-\mathbf{0 . 5 5 5 3}$ & 0.0553 & $\mathbf{0 . 4 7 2 8}$ & $\mathbf{- 0 . 5 3 8 6}$ \\
\hline
\end{tabular}

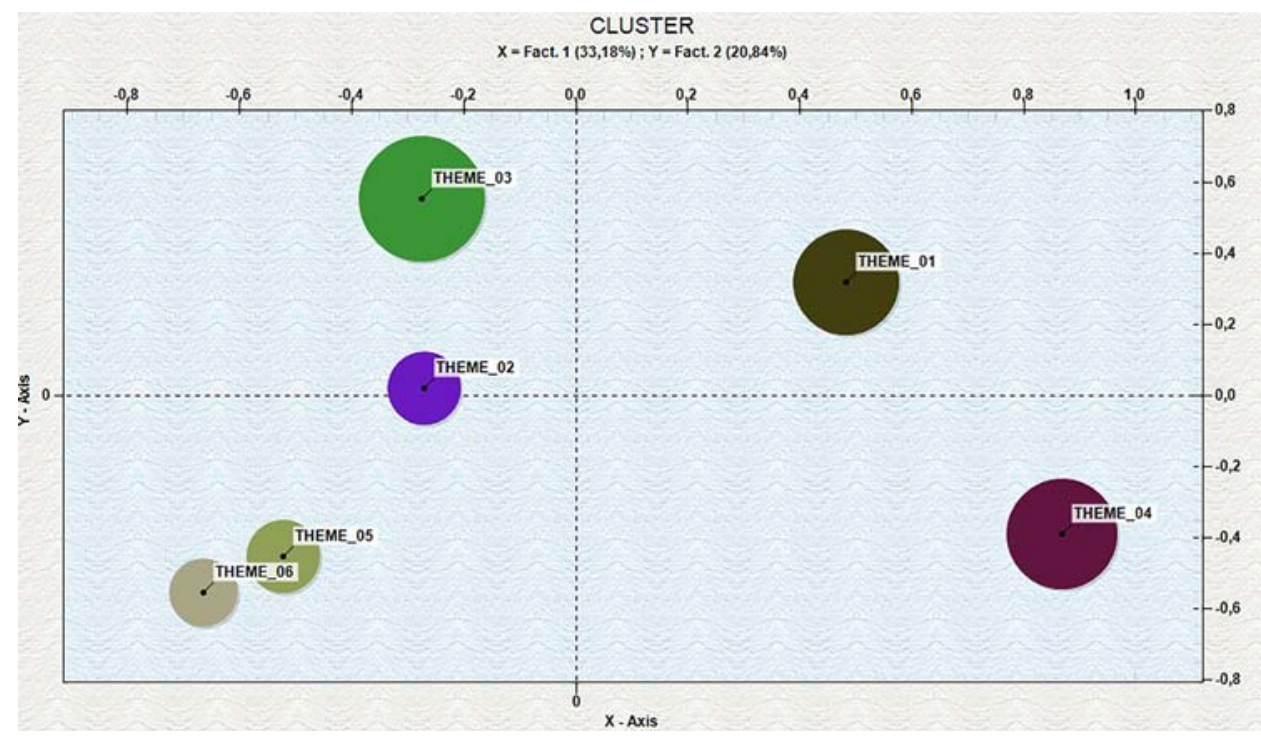

Figure 1. Disposition of clusters in factorial space (2D)

analysis produced a factorial space (Fig. 2) with five factors on which the clusters are positioned assuming the characteristics of opposite poles (Table 3). Each factor accumulates a certain amount of textual data (measured in terms of eigenvalue) (Table 4); their order is established by the greater amount of data it collects. The first factor corresponded to the horizontal axis $(X)$, cluster 4 (cos. 0.8683 ) and cluster 6 (cos. -0.6658$)$ are opposed. The second factor, identified with the vertical axis (Y), is represented by the opposition between cluster 3 (cos. 0.5550) and cluster 6 (cos. -0.5553). Furthermore, for the third factor, the perpendicular axis (Z) - only representable in a three-dimensional space -, cluster 1 (cos. 0.6903) and cluster 3 (cos. -0.4374) are opponent. The remaining factors have small dimensions (see Table 4) and their interpretation has limited relevance for the general understanding of the phenomenon.

\section{Cluster 1 - needs to change and complains}

\section{Illustrative variables: moved, low education level, graduated}

This cluster emphasizes the sense of frustration that the interviewees express considering the relationship between the condition of youth and the context of belonging. The most 


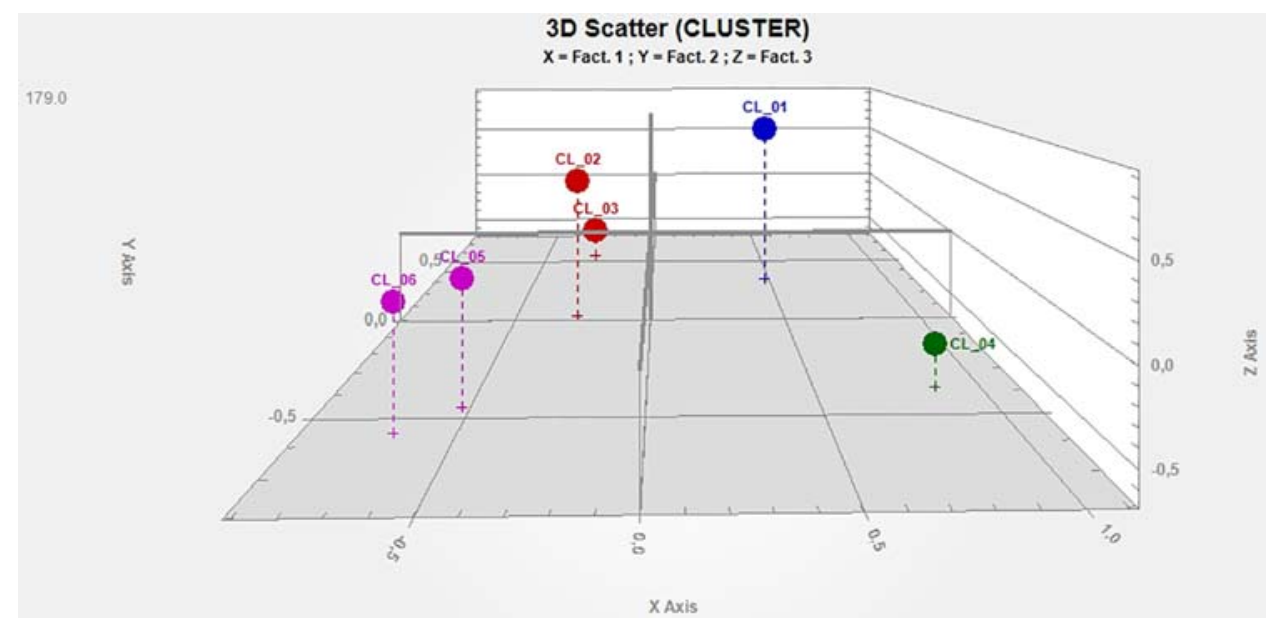

Figure 2. Grafic presentation of factorial space (3D Scatter) showing the disposition of clusters the factors $X, Y$ and $Z$.

pronounced word is the verb to change, the need to modify the current environment in relation to the issue of perceived safety. Following the words ideal and problem, an ideal condition, another reality is evoked in contrast to the high challenges perceived in the community. Three verbs are mentioned immediately after, to look for, to improve, to create, and all three express and emphasize actions aimed at a hypothetical transformation in order to reverse the adversities of the current context and to make it more successful for the youth.

Soon after, a feeling of degradation emerges: the dirty streets should be cleaned up. A general sense of environmental deterioration is also evoked by talking about pollution. Furthermore, another painful note is the presence of a difficult mentality, an expression which alludes to the limitation and closure of the local culture shared by common sense (person, people). Conclusively, the presence of crime is mentioned as an additional element of local socio-cultural depredation. The illustrative variables indicate that the sense of dissatisfaction becomes more exasperated in those who are not native to the place and, through the whole youth population without distinction, amongst those who have a degree or a diploma. This cluster is the expression of the most fragile and poor families who have moved to the suburbs due to economic problems.

Table 4. Eigenvalues, percentage and cumulative percentage of each factor.

\begin{tabular}{lccc}
\hline Factors & Eigenvalues & Percentage & Cumul. Percentage \\
\hline 1 & 0.3029 & 33.1758 & 33.1758 \\
2 & 0.1903 & 20.8436 & 54.0194 \\
3 & 0.1863 & 20.4079 & 74.4273 \\
5 & 0.1246 & 13.6489 & 88.0762 \\
6 & 0.1089 & 11.9238 & 100.0000 \\
\hline
\end{tabular}




\section{Cluster 2 - Leaving the place of origin, a difficult task}

\section{Illustrative variables: big neighborhood; young (18-23)}

In this cluster, young people discuss their housing and family contexts in relation to their needs. They talk about them in an ambiguous way. In the first part words like pleasure, tranquility and beauty emerge, which connote the homes of the young people interviewed. Immediately afterwards, however, a sense of limitation emerges in relation to the people with whom they live, whether they are family members or inhabitants. These relational spaces are considered 'small' related to the limited social opportunities they offer. Immediately after there is the verb to leave, parents coming to mind first, and a separation emerges in connection with the aspirations to move, to reside elsewhere. Leaving the family and place of origin is considered tiring (fatigue), which implies a violent break, to quarrel with the parents, without finding any mutual understanding (Cook 2020). The illustrative variables associated indicate, included among young people under 23 , 'the age of possibility' (Arnett 2000), for those who most probably plan to move elsewhere in the future (Arcidiacono, Procentese, and Di Napoli 2007). This culture, represented by young people under 23 , is also associated with residents of medium-large municipalities, where relational constraints and place attachment are not sufficient to cope with the lack of opportunities in the area and where anomie is greater.

\section{Cluster 3 - relational opportunities: entertainment and university}

Illustrative variables: big neighborhood; young (18-23)

This cluster describes the life of young people in relation to the proposals offered by large urban centres. The most common word is Naples, the most developed urban centre in the area, as well as in southern Italy. It is the place to build new friendships (friends), on both informal occasions (party), as well as at university. Studying and going out together in evening activities are the ways in which young people spend their time with peers and that make them feel different from when, for example, they are at home or with their family. Speaking of empowering relationships, young people also positively report that the local communities manifest aggregative-identifying power, such as sacred feasts around the fire, processions dedicated to patron saints and Our Lady. This culture is specific to young university students (18-23 years old).

\section{Cluster 4 - hopes and future projects}

\section{Illustrative variables: male; young-adult (24-34); small-medium neighborhood}

This cluster summarizes how young people symbolize their future and the planning process that will make them adults. The most common word is hope, as the youth expect to find their own way by building and realizing projects with which a future realization is associated. The interviewees think of being able to start from the position of being young to propose initiatives, hoping to be heard. By whom? By local administrations, and local politicians (town council, the municipality). This generation asks to be taken into consideration by discharging its availability to put itself at the service of territorial development, adhering to local volunteer initiatives that are headed by the Mayor. It should be 
noted that this culture is mostly the expression of the male group of young adults, mainly residents in small residential centers, places where favoritism is most present.

\section{Cluster 5 -Growth in informal and extended family contexts}

\section{Illustrative variables: female, native, high school diploma}

This cluster represents the development process in which young people register their growth towards adulthood. The key word of this repertoire of words is growth, becoming adults. Here too, as in cluster 4, the future is at stake. This cluster, in contrast to the previous one, is an expression of female culture, and in particular of those who did not continue with university studies and who are originally from the place. Becoming adults is associated with a bond of friendship with relatives and family, those of one's origin, but also in terms of building one's own family. Kinship is central. The relation with those closest is based on the role played in the family. Two verbs follow, to begin something, which alludes to forming one's own family seen as a form of social institution, and to share similar experience with other members of the family, such as brothers or cousins who have also left their family of origin or become parents (mothers).

\section{Cluster 6 - anchoring to the past}

\section{Illustrative variables: female, native, high school diploma}

The last cluster gathers the experiences and relationships lived in the past as the basis of the process of building youth identity. Considering their present, young people attribute great importance to memories and their ability to bond and link to different experiences; at school (Saraví, Bayón, and Azaola 2020) and the childhood home are the places where respondents learned to play and had their first relationships with peers as well as with cousins. In reflecting on their youthful condition, respondents are reminded of other earlier stages of development, such as childhood and adolescence, which are viewed with nostalgia (Cañón Rodríguez, Marín, and Fasanelli 2018; Cuervo and Cook 2019). Like the previous cluster, this one is also the predominant expression of native female young people.

\section{Summary of the factors}

\section{First factor - past and future}

Cluster 4 vs cluster 6 . This factor expresses the construction of identity for young Neapolitan people across their life span. They mostly express a conflict between the life spent so far and their challenges for the future. School friends, relatives and the places they played with friends played an important role in their social identity (Giardiello 2017), but none of them are mentioned in relation to their own future. These relationships are kept alive only through their memories. The future, instead, is related to the need to earn money and then the hope of getting a job in a reality dominated by youth unemployment. The opposition between these two clusters highlights the fact that the context is able to meet the educational and relational needs of children/adolescents, but not to provide their autonomy in the following developmental stages. The opposition between these two clusters also highlights a large gender gap. Young men consider the realization of projects and 
work expectations as goals towards adulthood, while the young girls, on the other hand, consider taking care of family relationships and cherishing the past as adult goals.

\section{Second factor - chosen relationships vs constricting relationships}

Cluster 3 vs cluster 6 . The experiences with family members, childhood friends and relatives contrast with university and recreational ones. Their contrast highlights a difference in the functions that these two types of relationships provide, the former being linked to an exploration of relationships between peers, in which there is a greater sense of freedom and novelty, while the latter, instead, are more functional in terms of a desire for attachment and reassurance within solid and secure bonds. Synthetically, for the young interviewees, human tradition and social innovations are strongly experienced in discontinuity.

\section{Third factor - sense of isolation and sociability}

Cluster 1 vs cluster 3. This factor expresses the presence of two emotional states. On one hand, young Neapolitans demonstrate a pervasive sense of powerlessness in relation to the degrading macro-contextual conditions. Faced with these problems, one feels alone and abandoned. Otherwise, young people feel they can experiment and be protagonists in other areas, such as in relation to their peers, with whom they share experiences of studying together and participating in city life. The ties with peers are experienced with a vital feeling of trust and sharing.

\section{Discussion}

This study revealed how young Neapolitans between the ages of 18 and 34 experience social relationships and imagine their future, in a deprived context in southern Italy.

It is a local culture that mostly gathers the experience of Millennials and a first tranche of Generation Z in a disadvantaged context in Southern Europe in the period of the posteconomic crisis and we will further outline it in this section.

The interpretative categories that emerge from a bottom-up analysis through the Emotional Textual Analysis present us with the complexity of the affective experiences that these young people face daily and the difficulty of making choices in a situation of increasing instability and unsustainability in terms of their particular context, and this is in line with the study of Spanò and Domecka (2020).

The idea of personal development expressed by these young people, as emerges from our data, is of great relevance. Although they talk about the future (see cluster 4), a careful reading reveals how their commitment is characterized only by desires and a strong hope for social change, but not any active involvement. The perception of not being able in any way to affect the local reality that is not oriented towards the development and satisfaction of its citizens, and the awareness of living in a system of family coexistence rules, leads to the limiting of all expectations for the future in the dimensions that depend on the characteristics of a stagnant context and the reluctant development of the resources that inhabit it. In the last 30 years, this feeling of perceiving oneself to be without power in relation to the public dimension, of being able to provide a direction without destiny, has taken root, and spread, a serious feeling of learned helplessness (Maier and Seligman 1976) in the population, especially in the weakest groups, such as 
young people, that is, adults who feel frustrated by the impossibility of finding a job or entering a meritocratic professional environment during the period of life (25-34 years), after having dedicated the first part of their youth to university studies or to practicing.

It appears to us as a profoundly problematic element of the youth culture that needs to be taken into consideration to build and share alliances of power with the groups that administrate and control the territory. Affiliation to systems of power seems to be more reassuring than finding oneself alone, building one's own path, or future, in a hostile context.

Now we will provide some features of the youth group aged 18-24 (Generation Z). Usually, this period is the time when young people, after graduation, approach the world of work through seasonal jobs, professional internships etc., or undertake a degree program at one of the local universities. It is surprising in terms of the latter that instead of considering the academy as a place of professional development through which to learn from the experience of professors and their relationships in the world of work, they consider that the only academic contexts in which resources can be considered true and genuine are those where they have relationships with their peers (see cluster 3). Surprisingly, the process of studying at university is not related to the possibility of finding a job with a higher education level. Thinking about your future, especially if you plan to attain a job position related to the degree obtained, brings out the probability of having to move elsewhere. It is a doubt that remains and finds space, even if moving does not take place due to lack of trust and social support. Undoubtedly, considering mobility underlies a conflictual relationship between the present and the future (Cuzzocrea and Mandich 2016), which in this case is represented as a very distressed moment, which should imply a separation with the whole relational context, too often too painful to carry out. It is evident that the bond with the local community has an identarian role even if it is only a place of regret and constraints. While the feeling of agency is mortified, the exaltation of the sense of belonging to places and to the family of origin takes shape, often becoming a relationship of unbreakable attachment that is necessary to survive in a context of oppression.

Another issue related to the latter concerns the sense of isolation and helplessness involved in living in one's neighborhood. It is evident that living in a deprived and unpredictable geographical area induces pervasive frustrating effects (see cluster 1). Furthermore, dissatisfaction with and anger towards the degraded context, as well as living in a district with a mistrust towards emerging people and a tendency to isolate the weakest sections of the population, keeps young people trapped in a sense of segregation and socio-cultural poverty. This leads to a feeling of presentification (Leccardi 2006) and individualism that inhibits all forms of prosociality and participation in the community and the development of social empowerment. It seems interesting to note that as an antidote to the sense of isolation and helplessness, the presence of security is invoked in defense of a generalized enemy, towards which one can pour one's helpless anger, a slogan often used by some factions from the far-right and those which are nationalistinspired.

Finally, we would like to address the issue of the family and the role that it plays for young people (Wyn, Lantz, and Harris 2012). The family context is the only space that escapes the clientelist and prevalence system described in relation to the culture that succumbs to the labor market and the administration of public policies. Let us remember, the 
family is a private context, therefore it does not necessarily share the same rules of urban and community culture. Here it is useful to underline the function that young people attribute to the family in their relationship with the outside world, that is, in that place where they can find their own fulfilment. The family of origin is experienced as a source of support on which it is possible to rely. This guarantees a system of relationships within it that ensures a sense of protection, care and emotional sharing. At the same time, the family home and the relationship with those who frequent it (close relatives, other members of the extended family, or family friends) are the bonds of belonging to the territory. Providing comfort and mutual assistance within kinship systems seems to be the way to cope with a power that governs the city and from which one feels excluded. However, limitations of this resource are understood. If this care function seemed effective during childhood and adolescence, during the period of youth it becomes a bond. It is difficult for young people to share with previous generations, especially their parents, the tightening of the labor market and social anomie. Often the parents, also helpless in a hostile context, do not support the transfer of one of their adult children elsewhere to look for a decent job. Instead they offer to support adult life and the potential new family of the young person, who barters their independence to be able to acquire a sense of mastery and more linear development in relation to the phases of life, such as passing from being children to becoming parents. Therefore, in our contexts we appreciated the supportive role of familiar cohesion, but we verify that it is not accompanied by civic attitudes of the respondents and their involvement in youth mutualism projects (Cuzzocrea and Collins 2015) or in a regeneration of the political landscape (Pickard and Bessant 2018). In fact, connections with the place emphasize memories and family roots but these do not give strength to autonomous projects (cluster 6).

A particular consideration concerns the role of young women living in the metropolitan area of Naples. The situation appears particularly alarming and disheartening. Once again, the woman emerges as the one who abdicates relations with the outside world to deal with relations between family members and extended kinship. She takes care of the growth of the offspring, the relationship with the neighborhood and maintains contacts with school, church, family and friends. The data analysis associated the variable 'young woman' with the clusters of words concerning the themes of family management and being the custodian of memory and traditions (cluster 5 and cluster 6 ) exclusive to young female culture. Another gender issue concerns the hope of finding a job (cluster 4 ), and this theme is exclusively characterized as a target of young males. Due to the difficulty of entering a labor market full of obstacles and with limited access, young women tend more easily to give up the pursuit of satisfaction in the professional sphere and to occupy a more traditional role, as a wife or mother, even after having obtained a degree.

\section{Conclusion}

The research has shown that the youth culture of the Province of Naples is characterized by a sense of powerlessness in relation to the development of one's own planning. The lack of job opportunities, and environmental degradation, as well as the presence of the underworld, push young people to having a great sense of distrust towards the community. The only glimmers of hope are the family of origin and the social relationships 
experienced in informal and higher educational contexts. However, on the one hand, the family culture does not seem to be able to understand and cope with the changes and work difficulties of the new generations compared to the generation of baby boomers (parents of hateful young people) who easily found employment during the economic boom in Italy that occurred in the 70s. On the other hand, relationships with peers are more aimed at sharing experiences that are emotionally strong in the present rather than organizing themselves into groups dedicated to proactivity and the incubation of ideas and projects. Particularly alarming is the condition of young women, for whom the world of work is perceived as one they are precluded from entering, just as establishing distance from the ties of origin and family is considered a source of anomie.

In conclusion, we consider it relevant that the future direction of youth research will have to investigate the corrosive effects of the Covid-19 pandemic, its restrictions and lockdowns, on an already precarious labour market, socialization processes and the future aspirations of the current youth generation.

\section{Disclosure statement}

No potential conflict of interest was reported by the authors.

\section{ORCID}

Agostino Carbone (1) http://orcid.org/0000-0003-0249-8888

Immacolata Di Napoli (D) http://orcid.org/0000-0002-7255-7735

Fortuna Procentese (1) http://orcid.org/0000-0002-1617-0165

Caterina Arcidiacono (i) http://orcid.org/0000-0003-3699-6981

\section{References}

Alfieri, S., D. Barni, R. Rosnati, and E. Marta. 2014. "“Do not Leave Your Values at Home": A Study of Value Orientations of Italian Emerging Adults and Their Parents." Psykhe 23 (2): 1-12.

Anđić, T. 2020. "Futurelessness, Migration, or a Lucky Break: Narrative Tropes of the 'Blocked Future'among Serbian High School Students." Journal of Youth Studies 23 (4): 430-446. doi:10. 1080/13676261.2019.1612048.

Andres, L., and M. Adamuti-Trache. 2008. "Life-course Transitions, Social Class, and Gender: A 15Year Perspective of the Lived Lives of Canadian Young Adults." Journal of Youth Studies 11 (2): 115-145. doi:10.1080/13676260701800753.

Anton, C. E., and C. Lawrence. 2014. "Home is Where the Heart is: The Effect of Place of Residence on Place Attachment and Community Participation." Journal of Environmental Psychology 40: 451461. doi:10.1016/j.jenvp.2014.10.007.

Arcidiacono, C., F. Procentese, and I. Di Napoli. 2007. "Youth, Community Belonging, Planning and Power." Journal of Community and Applied Social Psychology 17 (4): 280-295. doi:10.1002/casp. 935.

Arnett, J. J. 2000. "Emerging Adulthood: A Theory of Development from the Late Teens Through the Twenties." American Psychologist 55 (5): 469-480. doi:10.1037/0003-066X.55.5.469.

Arnett, J. J., R. Žukauskienè, and K. Sugimura. 2014. "The new Life Stage of Emerging Adulthood at Ages 18-29 Years: Implications for Mental Health." The Lancet Psychiatry 1 (7): 569-576. doi:10. 1016/S2215-0366(14)00080-7.

Bello, B. G., and V. Cuzzocrea. 2018. "Introducing the Need to Study Young People in Contemporary Italy." Journal of Modern Italian Studies 23 (1): 1-7. doi:10.1080/1354571X.2017.1409501. 
Bernardo, F., and J. M. Palma-Oliveira. 2012. “Place Identity: A Central Concept in Understanding Intergroup Relationships in the Urban Context." In The Role of Place Identity in the Perception, Understanding, and Design of Built Environments, edited by H. Casakin, and F. Bernardo, 35-46. Bentham Science Publishers

Bryant, J., and J. Ellard. 2015. "Hope as a Form of Agency in the Future Thinking of Disenfranchised Young People." Journal of Youth Studies 18 (4): 485-499. doi:10.1080/13676261.2014.992310.

Bucci, F., and S. Vanheule. 2020. "Investigating Changing Work and Economic Cultures Through the Lens of Youth Employment: A Case Study from a Psychosocial Perspective in Italy." Young 28 (3): 275-293. doi:10.1177/1103308819857412.

Buzzi, C., A. Cavalli, and A. de Lillo. 2007. Rapporto Giovani. Sesta Indagine Dell'Istituto IARD Sulla Condizione Giovanile in Italia [Youth Report. Sixth Study of the IARD Institute on the Italian Youth Conditions]. Bologna: II Mulino.

Cairns, D. 2014. Youth Transitions, International Student Mobility and Spatial Reflexivity: Being Mobile? Basingstoke: Palgrave McMillan.

Cairns, D., N. de Almeida Alves, A. Alexandre, and A. Correia. 2016. Youth Unemployment and job Precariousness: Political Participation in the Austerity era. Basingstoke: Palgrave Macmillan.

Cairns, D., K. Growiec, and N. de Almeida Alves. 2014. "Another 'Missing Middle'? The Marginalised Majority of Tertiary-Educated Youth in Portugal During the Economic Crisis." Journal of Youth Studies 17 (8): 1046-1060. doi:10.1080/13676261.2013.878789.

Cañón Rodríguez, M. F., D. Marín, and R. Fasanelli. 2018. "Pensando en la Salud de Niños y Niñas, el Aporte Desde las Representaciones Sociales." Revista Infancias Imágenes 17 (2): 197-208.

Carli, R., and R. M. Paniccia. 2002. Analisi Emozionale del Testo [Emotional Textual Analysis.]. Milano: FrancoAngeli.

Carli, R., R. M. Paniccia, F. Giovagnoli, A. Carbone, and F. Bucci. 2016. "Emotional Textual Analysis." In Handbook of Methodological Approaches to Community-Based Research: Qualitative, Quantitative, and Mixed Methods, edited by L. A. Jason, and D. S. Glenwick, 111-120. New York, NY: Oxford University Press.

Cavalli, A., and C. Leccardi. 2013. "Le Quattro Stagioni Della Ricerca Sociologica sui Giovani [The Four Seasons of Sociological Research on Young People]." Quaderni di Sociologia 62: 157-169. doi:10. 4000/qds.464.

Cook, J. 2020. "Keeping it in the Family: Understanding the Negotiation of Intergenerational Transfers for Entry Into Homeownership." Housing Studies 1-19. doi:10.1080/02673037.2020.1754347.

Cook, J., and D. Woodman. 2020. "Belonging and the Self as Enterprise: Place, Relationships and the Formation of Occupation-Based Identities." Sociologia Ruralis 60 (2): 375-393. doi:10.1111/soru. 12285.

Cops, D., S. Pleysier, and J. Put. 2012. "Worrying About the Future and Fear of Crime among Young Adults: a Social Psychological Approach." Journal of Youth Studies 15 (2): 191-205. doi:10.1080/ 13676261.2011.635193.

Côté, J., and J. M. Bynner. 2008. "Changes in the Transition to Adulthood in the UK and Canada: The Role of Structure and Agency in Emerging Adulthood." Journal of Youth Studies 11 (3): 251-268. doi:10.1080/13676260801946464.

Crocetti, E., and W. Meeus. 2014. "'"Family Comes First!" Relationships with Family and Friends in Italian Emerging Adults." Journal of Adolescence 37 (8): 1463-1473. doi:10.1016/j.adolescence.2014.02. 012.

Cuervo, H., and J. Cook. 2019. "Formations of Belonging in Australia: The Role of Nostalgia in Experiences of Time and Place." Population, Space and Place 25 (5): e2214. https:// doi.org/ 10.1002/psp.2214

Cuervo, H., and J. Wyn. 2014. "Reflections on the use of Spatial and Relational Metaphors in Youth Studies." Journal of Youth Studies 17 (7): 901-915. doi:10.1080/13676261.2013.878796.

Cuzzocrea, V., and R. Collins. 2015. "Collaborative Individualization? Peer-to-Peer Action in Youth Transitions." Young 23 (2): 136-153. doi:10.1177/1103308815569390.

Cuzzocrea, V., and G. Mandich. 2016. "Students' Narratives of the Future: Imagined Mobilities as Forms of Youth Agency?" Journal of Youth Studies 19 (4): 552-567. doi:10.1080/13676261.2015. 1098773. 
Di Blasi, M., C. Tosto, A. Marfia, P. Cavani, and C. Giordano. 2016. "Transition to Adulthood and Recession: a Qualitative Study." Journal of Youth Studies 19 (8): 1043-1060. doi:10.1080/ 13676261.2015.1136055.

Di Martino, S., I. Di Napoli, C. Esposito, I. Prilleltensky, and C. Arcidiacono. 2018. "Measuring Subjective Well-Being from a Multidimensional and Temporal Perspective: Italian Adaptation of the I COPPE Scale." Health and Quality of Life Outcomes 16 (88): 1-11. doi:10.1186/s12955018-0916-9.

Di Napoli, I., P. Dolce, and C. Arcidiacono. 2019a. "Community Trust: Social Indicator and Predictor of Community Engagement." Social Indicator Research 145 (2): 551-579. doi:10.1007/s11205-01902114-y.

Di Napoli, I., C. Esposito, L. Candice, and C. Arcidiacono. 2019b. "Trust, Hope, and Identity in Disadvantaged Urban Areas." The Role of Civic Engagement. Community Psychology in Global Perspective 5 (2): 46-62. doi:10.1285/i24212113v5i2p46.

Di Napoli, I., F. Procentese, and C. Arcidiacono. 2019c. "Women's Associations and the Well-Being of Their Members: From Mutual Support to Full Citizenship." Journal of Prevention \& Intervention in the Community 48 (2) 189-205. doi:10.1080/10852352.2019.1624357.

EGRIS (European Group for Integrated Social Research). 2001. “Misleading Trajectories: Transitional Dilemmas of Young Adults in Europe." Journal of Youth Studies 4 (1): 101-119. doi:10.1080/ 13676260120028574.

EUROSTAT. 2018. Euro area unemployment. https://ec.europa.eu/eurostat/documents/2995521/ 9105174/3-31072018-AP-EN/a942605d-7a19-4c0a-8616-c5805a826798.

Farrugia, D. 2019. Spaces of Youth: Work, Citizenship and Culture in a Global Context. London: Routledge.

Fasanelli, R., I. Galli, M. G. Grassia, M. Marino, R. Cataldo, C. N. Lauro, C. Castiello, F. Grassia, C. Arcidiacono, and F. Procentese. 2020. "The use of Partial Least Squares-Path Modelling to Understand the Impact of Ambivalent Sexism on Violence-Justification among Adolescents." International Journal of Environmental Research and Public Health 17 (14): 1-21. doi:10.3390/ ijerph17144991.

Feixa, C., M. Perondi, J. Nofre, A. Fernández-Planells, M. Figueras, V. Toscano, and T. López. 2012. “The Spanish Revolution and Beyond." Cultural Anthropology Online 1.

Galli, I., A. Liguori, F. Lorenzi-Cioldi, and R. Fasanelli. 2019. "Men, Women, and Economic Changes: Social Representations of the Economic Crisis." Interdisciplinaria 36 (2): 283-298. ISSN: 1668-7027.

Giardiello, M. 2017. "The Neglected Educative Function of Public Space on Preadolescent Development." The Journal of Early Adolescence 37 (6): 737-759.

Giardiello, M. 2020. "Civic Theory and Educative Processes in Informal Spaces: A Case Study in Three Italian Realities." In A. Peterson et al. (eds.) The Palgrave Handbook of Citizenship and Education, 705-719.

Habib, S., and M. R. Ward, eds. 2019a. Youth, Place and Theories of Belonging. London: Routledge.

Habib, S., and M. R. Ward. 2019b. "Introduction: Investigating Youth and Belonging." In Youth, Place and Theories of Belonging, edited by S. Habib, and M. R. Ward, 1-11. London: Routledge.

Habib, S., and M. R. Ward. 2019c. "Conclusion: Young People Negotiating Belonging in Changing Times." In Identities, Youth and Belonging, edited by S. Habib, and M. R. Ward, 195-212. London: Routledge.

Harvey, D. 2001. Spaces of Capital: Towards a Critical Geography. London: Routledge.

Heggli, G., H. Haukanes, and M. Tjomsland. 2013. "Fearing the Future? Young People Envisioning Their Working Lives in the Czech Republic, Norway and Tunisia." Journal of Youth Studies 16 (7): 916-931. doi:10.1080/13676261.2013.766682.

Hernandez, B., M. C. Hidalgo, M. E. Salazar-Laplace, and S. Hess. 2007. “Place Attachment and Place Identity in Natives and non-Natives." Journal of Environmental Psychology 27 (4): 310-319. doi:10. 1016/j.jenvp.2007.06.003.

Howie, L., and P. Campbell. 2016. “Guerrilla Selfhood: Imagining Young People's Entrepreneurial Futures." Journal of Youth Studies 19 (7): 906-920. doi:10.1080/13676261.2015.1123236.

ISTAT. 2019. Rapporto benessere equo e sostenibile (BES) [Fair and sustainable wellness relationship]. https://www.istat.it/it/archivio/rapporto+bes. 
Kintrea, K., R. St Clair, and M. Houston. 2015. "Shaped by Place? Young People's Aspirations in Disadvantaged Neighbourhoods." Journal of Youth Studies 18 (5): 666-684. doi:10.1080/ 13676261.2014.992315.

Lancia, F. 2012. T-LAB Pathways to thematic analysis. http://www.mytlab.com/tpathways.pdf.

Leccardi, C. 2005. "Facing Uncertainty: Temporality and Biographies in the New Century." Young. Nordic Journal of Youth Research 13 (2): 123-146. doi:10.1177/1103308805051317.

Leccardi, C. 2006. "Redefining the Future: Youthful Biographical Constructions in the 21st Century." New Directions for Child and Adolescent Development 113: 37-48. doi:10.1002/cd.167.

Leccardi, C. 2008. "New Biographies in the 'Risk Society'? About Future and Planning." Twenty-first Century Society 3 (2): 119-129. doi:10.1080/17450140802062078.

Leccardi, C. 2012. "Young People's Representations of the Future and the Acceleration of Time: a Generational Approach." Diskurs Kindheits-und Jugendforschung/Discourse. Journal of Childhood and Adolescence Research 7 (1): 59-73.

Leccardi, C. 2017. "The Recession, Young People, and Their Relationship with the Future." In Young People's Development and the Great Recession: Uncertain Transitions and Precarious Futures, edited by I. Schoon, and J. Bynner, 348-371. Cambridge: Cambridge University Press.

Leccardi, C. 2020. "Young Italians: Individualization, Uncertainty and Reconquesting the Future." In Italian Youth in International Context: Belonging, Constraints and Opportunities, edited by V. Cuzzocrea, B. G. Bello, and Y. Kazepov, 171-184. London: Routledge.

Leccardi, C., V. Cuzzocrea, and B. G. Bello. 2018. "Youth as a Metaphor: An Interview with Carmen Leccardi." Journal of Modern Italian Studies 23 (1): 8-23. doi:10.1080/1354571X.2017.1409522.

León, M., and M. Migliavacca. 2013. "Italy and Spain: Still the Case of Familistic Welfare Models?" Population Review 52 (1) 25-42. doi:10.1353/prv.2013.0001.

Leone, S., and A. Rubin. 2019. "Giovani al Sud e in Italia tra continuità e cambiamento [Young People in the South and in Italy Between Continuity and Change]." In La condizione giovanile in Italia [Youth Condition in Italy], edited by ISTITUTO GIUSEPPE TONIOLO, 215-238. Bologna: II Mulino.

Maier, S. F., and M. E. Seligman. 1976. "Learned Helplessness: Theory and Evidence." Journal of Experimental Psychology: General 105 (1): 3-46. doi:10.1037/0096-3445.105.1.3.

Mary, A. A. 2014. "Re-evaluating the Concept of Adulthood and the Framework of Transition." Journal of Youth Studies 17 (3): 415-429. doi:10.1080/13676261.2013.853872.

Molgat, M. 2007. "Do Transitions and Social Structures Matter? How 'Emerging Adults' Define Themselves as Adults." Journal of Youth Studies 10 (5): 495-516. doi:10.1080/13676260701580769.

Montella, A., V. Marzano, F. Mauriello, R. Vitillo, R. Fasanelli, M. Pernetti, and F. Galante. 2019. "Development of Macro-Level Safety Performance Functions in the City of Naples." Sustainability 11 (7): 1-21. WOS:000466551600048.

Nico, M. 2014. "Variability in the Transitions to Adulthood in Europe: a Critical Approach to deStandardization of the Life Course." Journal of Youth Studies 17 (2): 166-182. doi:10.1080/ 13676261.2013.805877.

Paniccia, R. M., F. Giovagnoli, A. Caputo, G. Donatiello, and T. Cappelli. 2019. "The Failure of "Traditional Adult Goals" for Today's Young People: New Cohabitations and new Coexistences." Rivista di Psicologia Clinica 14 (2): 21-54. doi:10.14645/RPC.2019.2.785.

Pickard, S., and J. Bessant, eds. 2018. Young People re-Generating Politics in Times of Crises. Basingstoke, UK: Palgrave Macmillan.

Piumatti, G., L. Pipitone, A. M. Di Vita, D. Latina, and E. Rabaglietti. 2014. "Transition to Adulthood Across Italy: A Comparison Between Northern and Southern Italian Young Adults." Journal of Adult Development 21 (1): 1-12. doi:10.1007/s10804-013-9174-6.

Ravn, S., and J. Demant. 2017. "Figures in Space, Figuring Space: Towards a Spatial-Symbolic Framework for Understanding Youth Cultures and Identities." Young 25 (3): 252-267. doi:10. $1177 / 1103308816669256$.

Recksiedler, C., and R. A. Settersten. 2020. "How Young Adults' Appraisals of Work and Family Goals Changed Over the Great Recession: An Examination of Gender and Rural-Urban Differences." Journal of Youth Studies 23 (9): 1217-1233. doi:10.1080/13676261.2019.1663339.

Rosina, A. 2019. "Un Ritratto Dell'adulto Italiano da Giovane [A Portrait of the Italian Adult as a Young man]. In Rapporto Toniolo." In Istituto Giuseppe Toniolo (Ed.), La condizione giovanile 
in Italia. Rapporto giovani [Institute Giuseppe Toniolo (Ed.), Youth Condition in Italy, Youth Report] 7-19. Bologna: II Mulino.

Salvatore, S., and M. F. Freda. 2011. "Affect, Unconscious and Sensemaking. A Psychodynamic, Semiotic and Dialogic Model." New Ideas in Psychology 29 (2): 119-135. doi:10.1016/j. newideapsych.2010.06.001.

Sanderson, E. 2020. "Youth Transitions to Employment: Longitudinal Evidence from Marginalised Young People in England." Journal of Youth Studies 23 (10): 1310-1329. doi:10.1080/13676261. 2019.1671581.

Saraví, G. 2014. "Youth Experience of Urban Inequality: Space, Class, and Gender in Mexico." In: Wyn J., Cahill H. (eds) Handbook of Childhood and Youth, 1-11. Singapore: Springer.

Saraví, G. A., M. C. Bayón, and M. C. Azaola. 2020. "Constructing School Belonging (s) in Disadvantaged Urban Spaces: Adolescents' Experiences and Narratives in Mexico City." Youth \& Society 52 (7): 1107-1127. doi:10.1177/0044118X19838188.

Schoon, I., and J. Mortimer. 2017. "Youth and the Great Recession: Are Values, Achievement Orientation and Outlook to the Future Affected?" International Journal of Psychology 52 (1): 18. doi:10.1002/ijop.12400.

Schütze, F. 2014. "Autobiographical Accounts of War Experiences. An Outline for the Analysis of Topically Focused Autobiographical Texts - Using the Example of the "Robert Rasmus" Account in Studs Terkel's Book, "The Good War"." Qualitative Sociology Review 10 (1): 224-283.

Schwartz, S. J., J. E. Côté, and J. J. Arnett. 2005. "Identity and Agency in Emerging Adulthood: Two Developmental Routes in the Individualization Process." Youth \& Society 37 (2): 201-229. doi:10. $1177 / 0044118 \times 05275965$.

Serracant, P. 2012. "Changing Youth? Continuities and Ruptures in Transitions Into Adulthood among Catalan Young People." Journal of Youth Studies 15 (2): 161-176. doi:10.1080/13676261. 2011.643234.

Shildrick, T., S. Blackman, and R. MacDonald. 2009. "Young People, Class and Place." Journal of Youth Studies 12 (5): 457-465. doi:10.1080/13676260903114136.

Sica, L. S., E. Crocetti, G. Ragozini, L. Aleni Sestito, and T. Serafini. 2016. "Future-oriented or PresentFocused? The Role of Social Support and Identity Styles on 'Futuring'in Italian Late Adolescents and Emerging Adults." Journal of Youth Studies 19 (2): 183-203. doi:10.1080/13676261.2015. 1059925.

Spanò, A., and M. Domecka. 2020. "Pathways Towards Adulthood in Times of Crisis: Reflexivity, Resources and Agency among Young Neapolitans." In Italian Youth in International Context: Belonging, Constraints and Opportunities, edited by V. Cuzzocrea, B. G. Bello, and Y. Kazepov, 185-199. London: Routledge.

SVIMEZ. Associazione per lo sviluppo del mezzogiorno nell'industria. 2019. Rapporto L'economia e la Società del Mezzogiorno [Relationship The Economy and Society of the South]. Bologna: II Mulino.

Tyrell, F. A., and T. M. Yates. 2018. "Emancipated Foster Youth's Experiences and Perceptions of the Transition to Adulthood." Journal of Youth Studies 21 (8): 1011-1028. doi:110.1080/13676261. 2018.1441983.

Wyn, J., H. Cuervo, and J. Cook. 2018. "Expanding Theoretical Boundaries from Youth Transitions to Belonging and new Materiality." In Identities, Youth and Theories Belonging, edited by S. Habib, and M. R. Ward, 12-24. London: Routledge.

Wyn, J., S. Lantz, and A. Harris. 2012. "Beyond the 'Transitions' Metaphor: Family Relations and Young People in Late Modernity." Journal of Sociology 48 (1): 3-22.

Wyn, J., and R. White. 1996. "The Concept of Youth." In Rethinking Youth, edited by J. Wyn, and R. White, 8-25. London: Sage. 